\title{
Using authentic materials for students of tourism in Slovenia: English language acquisition for students of the Faculty of Tourism of the University of Maribor
}

\author{
Jasna Potočnik Topler \\ Faculty of Tourism of University of Maribor, \\ Brežice, Slovenia
}

\begin{abstract}
The article examines the process of teaching English for specific purposes at the Faculty of Tourism of the University of Maribor, Slovenia using coursebooks and authentic supplementary materials. The survey has shown that the students of the Faculty of Tourism prefer supplementary authentic materials to coursebooks because they find them sufficiently interesting or challenging. Specially designed classroom materials that are put into the Moodle by the teacher also offer opportunities for various activities in lesson planning for teaching, listening, speaking, reading and writing. Another important aspect of supplementary materials is that they facilitate the teacher's creativity. However, there are advantages and disadvantages to using only coursebooks or only specially prepared classroom materials, and both - coursebooks and supplementary materials - should be used only after careful consideration. Although authentic materials may contain complex grammatical structures and difficult vocabulary, they bring real-life situations into classrooms, and students therefore find them very motivating, the survey has shown.
\end{abstract}

Key words: coursebook; English for Specific Purposes; supplementary materials; authentic materials; cultural content.

\section{Introduction}

It seems that comparative studies on teaching English are gaining importance among researchers and teachers. The reason for that is probably that they help to understand different aspects of teaching and consequently creating, re-creating and improving English language curricula in different teaching programs at different faculties all over the world. The present study concentrates on teaching English for tourism sector in Slovenia. Data were collected through anonymous survey 
questions (questionnaires) based on Balič (2009) and through interviews. The aim of the paper is to examine some aspects of using the coursebooks, their advantages and disadvantages in comparison to authentic and cultural materials. Further on the process of teaching English for specific purposes at the Faculty of Tourism of the University of Maribor is presented and also some results of the survey in which the students of the Faculty of Tourism learning English were asked to give their feedback on English lessons and evaluate coursebooks and materials in the Moodle (the University's Virtual Learning Environment).

\section{Theoretical Background}

Being fluent in at least one foreign language is nowadays becoming a fact of life; and in the tourism sector, employees should be able to communicate not only in one, but in several foreign languages, and among them English of course holds the status of lingua franca. There is no question that English is the most widely taught, read, and spoken language that the world has ever known (Kachru and Nelson, 2001: 9). Not to use English in professional environment and also in social interaction seems almost impossible today - also in a small country called Slovenia. What is more, 'foreign languages are becoming the intellectual tool for the development of intercultural competence, in the sense of declarative knowledge and communication skills' (Balič, 2009: 1).

In ESP - English for Specific Purposes - the purpose for learning the language is extremely important and it is directly connected to what the learners need to do in their jobs or future professional careers. Harding (2007: 6) points out two elements of ESP: the sense of purpose and the sense of vocation, and argues that in ESP 'the practical application and use of language overrides other aspects of language learning.' Consequently, it has been argued that the ESP teacher has five major roles:

1 Teacher or language consultant,

2 Course designer and materials provider,

3 Researcher - not just gathering material, but also understanding the nature of the material of the ESP specialism,

4 Collaborator - working with subject teachers and subject teaching,

5 Evaluator - constantly evaluating the materials and the course design, as well as setting assessment tests and achievement tests (Harding, 2007: 7).

Since the goal of the Faculty of Tourism of the University of Maribor, Slovenia is to qualify the students for "real life", curricula have to change accordingly. Consequently, also the role of a teacher is changing. It is not enough to merely follow the curriculum. Instead, continuous improvement is needed. 'Teachers should be able 
to teach their learners how to develop, improve and use all the necessary skills required for successful linguistic communication' (Balič, 2009: 1).

\subsection{How necessary is a coursebook?}

ESP teachers in Slovenia have many dilemmas. One of them is whether a coursebook is necessary. Penny Ur (2001: 183) argues that in some schools, teachers cannot imagine work without coursebooks. In others, they may not be used at all because the teacher works according to a syllabus, or according to his or her own programme, using coursebooks and supplementary materials as the need arises. Ur also identifies a third situation or "compromise", wherein a coursebook is used selectively, not necessarily in sequence, and is extensively supplemented by other materials. Chou (2010) warns that 'the process of choosing the right coursebook for use in the classroom, especially at the college level, is a daunting task' and '/.../ coursebooks should be chosen based on their educational values and whether or not they meet the programme objectives.'

Ur (2001: 184-185) then proceeds to enumerate the pros and cons of coursebook use. She sees advantages in using a coursebook in a fact that a coursebook provides a clear framework (there is a sense of structure and progress), it serves as a syllabus, it provides texts and learning tasks which are usually suitable for most of the students of the class; it is usually the cheapest learning material and the most convenient package, which can provide useful guidance and support.

On the other hand, Ur (ibid.) also enumerates the disadvantages of using the coursebook. According to her, no coursebook can fully meet all requirements. The topics of the coursebook may not be relevant or interesting for the students, and may also inhibit a teacher's creativity, which may lead to lack of motivation on the part of the learners. Coursebooks do not usually cater to the range of levels of knowledge or ability that exists in most classes. Also, teachers sometimes find it too easy to function merely as mediators of coursebooks' contents.

Of course a coursebook should be approached critically, or, as Ur (187) points out, 'we should be aware of its good and bad points in order to make the most of the first and compensate for or neutralize the second'. The majority of ESP teachers would probably agree that most language-teaching coursebooks need to be supplemented at least to some extent, even if this only entails tailoring them to the needs of a particular student or class or extending a particular topic and offering richer options. For these reasons and the reasons listed above, it is probably easier for a teacher to use a coursebook. A set framework helps to manage the programme and time. Additionally, students often prefer to have a coursebook, mainly because they would like to avoid being too teacher-dependent. It is important to admit that the use of coursebooks definitely has its share of benefits. But it should also be noted that outside reading and listening materials could enhance student motivation, especially if students find the reading and listening activities in the 
coursebook uninteresting: 'The students who are using these ESL course books are young adults and they should be gaining knowledge from their readings, not just coming to class to practice English' (Chou, 2010).

Coursebooks present some clear advantages, but there are some drawbacks. All learners at the Faculty of Tourism of the University of Maribor in Brežice, Slovenia, and of course every class, have their own learning needs, which are conditioned by their previous knowledge and future career plans. Consequently, a coursebook alone cannot fully meet the needs of every student or the expectations of the teacher. The topics covered in the coursebook are often not particularly interesting for the students, and the set structure of a coursebook could inhibit the teacher's creativity. Obviously, a lot depends on the teacher's style and the resources available at the faculty. Teachers' experiences presented on English teachers'conferences in Slovenia show that many (exact figures are not known, because a survey on the subject has not been carried out yet) LSP teachers supplement the chosen or prescribed coursebooks; some even go a step further and avoid using them because they prefer to develop their own materials. An additional reason not having to do with curriculum and materials per se or student needs and teacher goals is that materials can be used to avoid unnecessary expenses for students. And, last but not least, it is very important that students, and especially tourism students, not only become fluent in speaking, but that they also become aware of cultural differences. Corbett (2003) writes on the subject in his book An Intercultural Approach to English Language Teaching. He understands learning a foreign language as an openended and continuing process in which we move from one set of linguistic and cultural contexts into others, each of which demands new efforts of translation and interpretation. According to Corbett (2003) the language learner moving between cultures 'is an intercultural learner and hence /.../ needs an intercultural approach to language teaching.' In Slovenia, a valuable contribution to the intercultural approach to English language teaching was made in 2001 by Šabec and Limon's coursebook Across Cultures. The authors believe that despite the fact that English is now a widely used "world language", it helps 'if we can relate the learning process to a specific culture or cultures' (Šabec \& Limon 2001: 12). Developing cultural awareness and cross-cultural communication skills has gained importance in recent years also in Slovenia. Tomalin \& Stempleski (1994: 7-8) provide the following 'seven goals of cultural instruction':

1. To help students to develop an understanding of the fact that all people exhibit culturally-conditioned behaviours.

2. To help students to develop an understanding that social variables such as age, sex, social class, and place of residence influence the ways in which people speak and behave.

3. To help students to become more aware of conventional behaviour in common situations in the target culture. 
4. To help students to increase their awareness of the cultural connotations of words and phrases in the target language.

5. To help students to develop the ability to evaluate and refine generalizations about the target culture, in terms of supporting evidence.

6. To help students to develop the necessary skills to locate and organize information about the target culture.

7. To stimulate students' intellectual curiosity about the target culture, and to encourage empathy towards its people.

\section{Implications for authentic and cultural materials}

Although the disadvantages of supplementary materials are widely acknowledged and total avoidance of coursebooks is not entirely unproblematic, at the Faculty of Tourism of the University of Maribor in Brežice, Slovenia the creation of supplementary, preparation of authentic and cultural materials is strongly supported by both students and, of course, their teacher. Special supplementary materials chosen by the teacher also give the students an opportunity to influence the teaching process (they for example tell their teachers what vocabulary they would like to learn), which is valuable for both students (they regularly express their needs and wishes) and for the teacher (students' wishes and suggestions represent important and immediate feedback for the teacher). The teacher puts the materials, links to video clips, exercises and other materials in the Moodle which is the University's virtual learning environment used to support the delivery of learning and teaching.

What are authentic materials? They can be defined as 'items created for the general native speaking population and have not been developed or adapted for second language learners. They were not designed for language teaching purposes, but their primary intent is to communicate messages to the native speakers of the language' (Balič, 2009:3).

Therefore, according to Balič (ibid.) they mean 'real language use' and they 'were not created with the purpose of language teaching in mind'. A lot of such materials are available everywhere, and especially of course on the Internet. They include articles, advertisements, menus, recipes, leaflets, brochures etc. Balič (2009: 5-6) divides authentic materials into three types: 1 authentic audio materials (TV programmes, movies, radio, taped conversations such as one-sided phone conversation, meetings, talks, announcements in airports and stores, professionally audio-taped short stories and novels etc.), 2 authentic visual materials (photographs, paintings and drawings, wordless street signs, pictures from magazines, postcards, wordless picture books, stamps, coins and currency, clocks, phones, holiday decorations etc.), and 3 authentic printed materials (newspapers, lyrics to songs, restaurant menus, street signs, food product labels, tourist information brochures, uni- 
versity catalogues, telephone books, magazines, maps, greeting cards, letters, mails, prescription labels etc.).

The benefit learners get from working with authentic materials is being exposed to the real language as it is spoken and used in the target language community, by the native speakers of the language. (Balič, 2009: 3)

The use of cultural and authentic content in the classroom is very important, especially for tourism students. Of course, teachers need to consider carefully what to include in the teaching materials and in what ways. By all means, chosen materials should reflect real-life situations. For tourism students in Slovenia, there are many benefits of including not only Slovene culture, but also a wide range of other cultures - not just British, American or Western culture - in classroom teaching materials. According to Balič (2009: 4) while working with authentic materials 'learners feel that they are learning the real language and that enables them to relate more closely with the target country and the target language itself'. What is more, cultural information helps the students understand the target culture better and develop critical thinking (Shanahan, 1997; cited in Balič 2009). Further on, Balič (2009: 5) also argues that authentic materials have a strong communicative function since they were initially designed for the native speakers. Hempkin \& Kline Majcenovič (2012) also point out that students learning English for a specific purpose face a dual challenge: 'not only are they expected to display a solid command of general language, but they must also acquire a set of specific terminology for use in their chosen field.' As far as tourism students are concerned, knowing a wide range of cultures and their concomitant cultural differences and similarities is of extreme importance for getting the message across successfully.

\section{Results}

Student feedback in class discussions and according to the survey indicates that students of the Faculty of Tourism in Brežice are well aware of the fact that English is a lingua franca in international business contexts and that learning English as a foreign language is high on their list of priorities. They seem motivated: the majority of them attend classes regularly (attendance is not obligatory) and they do their homework (homework is not obligatory, but optional). Some of the students even feel that the English language is so important for their future careers that they expressed a wish for additional hours of English $(6 \%$ of the students stated this under the open-ended question 'Do you have any additional comments?'; the number of additional hours was not specified). The sample consisted of 110 students in the Bachelor study programs at the Faculty of Tourism of the University of Maribor in Brežice. All the respondents were full-time students in their first and second years of the Bachelor program. The (anonymous) questionnaire was applied only to the students who attended classes on the day the survey was con- 
ducted and not to all the students enrolled. The sample consisted of 69 female and 41 male students. At the Faculty of Tourism female students prevail, and some teachers of the Faculty of Tourism believe that this fact is strongly related to motivation figures as they believe that female students are (according to their classroom experience) more motivated for studying. The students had an average of 19.6 years, which means that the majority of the respondents were very young people who were continuing their education after high school. It is also very interesting that only 5 students (4.5\%) answered that they would prefer more lessons based on coursebooks than on supplementary materials.

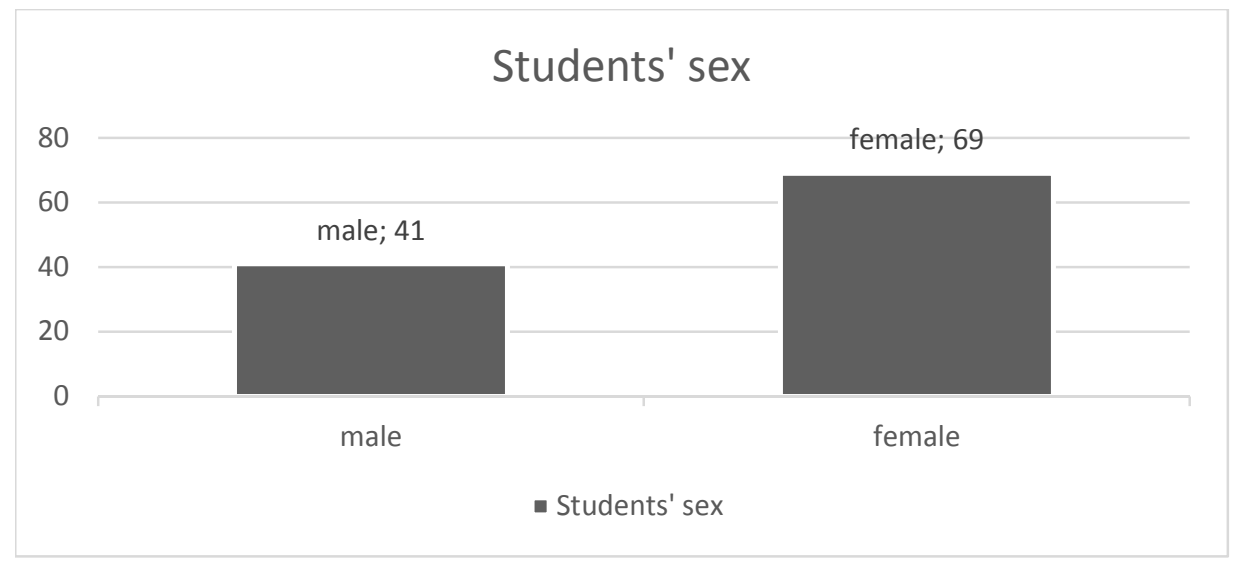

Figure 1: Students' sex

Figure 1 shows that since $62.7 \%$ of the participants were female and $37.3 \%$ were male, there were obviously a lot more female than male respondents to questionnaire. This information is interesting because the author's experience and experience of faculty's language teachers show that female students are more motivated for studying than male students, and consequently female students have better grades in English subjects than male students. 


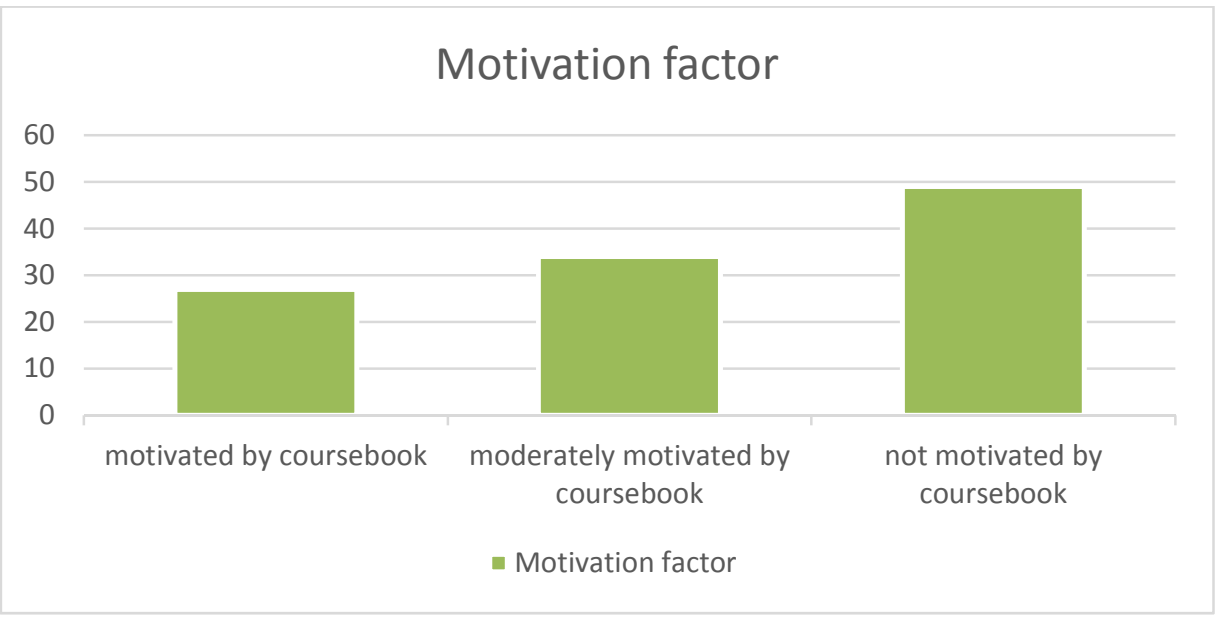

Figure 2: Motivation factor

Figure 2 shows that $24.5 \%$ of the respondents are motivated by their coursebook, $31 \%$ are moderately motivated and $44.5 \%$ are not motivated by their coursebook at all.

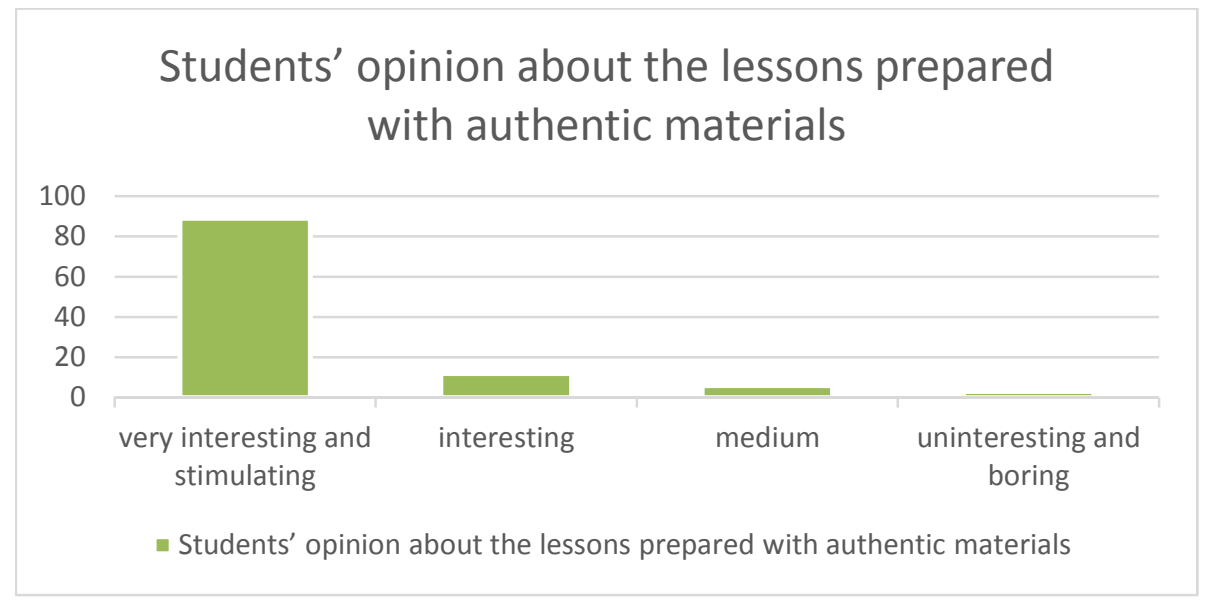

Figure 3: Students' opinion about the lessons prepared with authentic materials

Students were asked to state their opinions on the lessons taught and on the materials used. $81 \%$ of the students felt that the lessons prepared and carried out with authentic materials were very interesting and stimulating, $10.9 \%$ of them thought they were interesting, $5.4 \%$ of them felt that the presented lessons were 
medium interesting, whereas $2.7 \%$ of the students thought that the executed lessons were uninteresting and boring. (The exact question was: I find lessons in English course prepared and carried out with authentic materials a) very interesting and stimulating $\mathrm{b}$ ) interesting c) medium interesting d) uninteresting and boring).

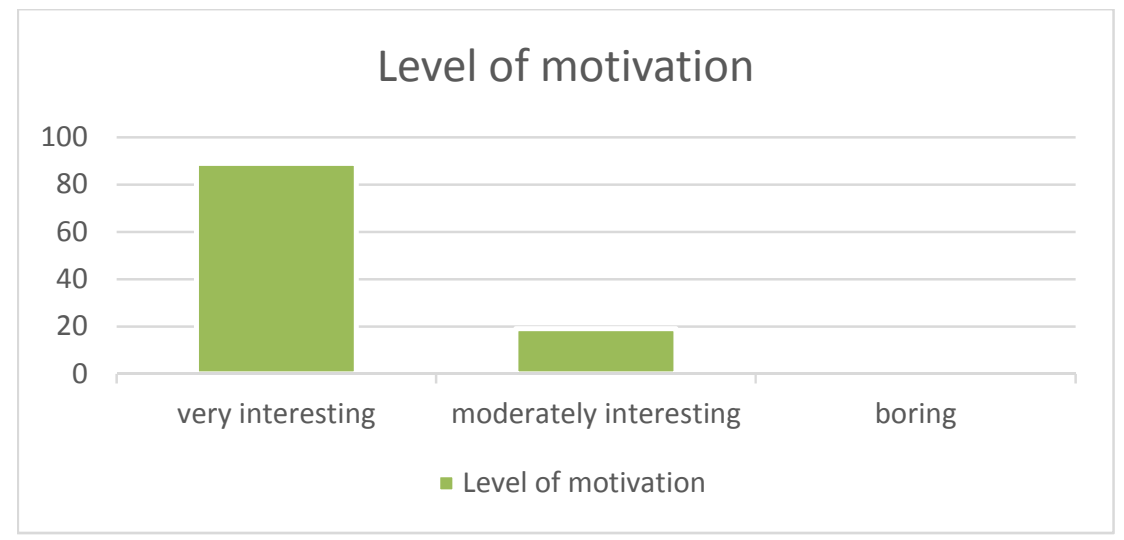

Figure 4: Level of motivation

$81 \%$ of the students regarded the authentic materials presented and used during the lessons as being very stimulating and motivating for their participation in class, $17.2 \%$ of them felt that the material was partly interesting and motivating, whereas only $1.8 \%$ of the students were not motivated by used authentic materials at all. (The exact question was: The authentic materials presented and used during the English lessons are: a) very stimulating and motivating b) partly interesting and motivating c) not motivating).

\section{Discussion}

Despite all these positive facts, motivating tourism students can sometimes be challenging. Faculty teachers' experience has shown that it is very important that the students see some kind of practical use in the prepared materials and tasks. Consequently, materials tend to be close to the real-life situations that tourism students are likely to encounter in their professional lives and during their obligatory work study. For these reasons, the resources are closely connected to all aspects of tourism, from restaurant and hotel English to dealing with complaints and compensation claims, negotiations and reading contracts. During the English lessons, newspaper and scientific articles on tourism are used. Films and documentaries about business, clips and films from YouTube, real-life business series, inter- 
views, guides and presentations, as well as excerpts from fictional or non-fictional works on travel (the works of Bill Bryson for example), are also used.

Chou (2010) says that with the use of outside reading materials, the teacher can also design many different activities for the classroom. For example, if the class is reading an excerpt from a book, the teacher can use class discussions as a form of conversation practice. Teachers can also have students do different kinds of presentations (presentation of the favourite holiday destination or the worst holidays service ever, presentation of cultural attractions or some festival's events etc.) based on their readings. These activities are usually more challenging for the students than the question and answer activities found in recommended ESL coursebooks (English for International Tourism by Jacob \& Stuart). The students of the Faculty of Tourism also seem very motivated by authentic materials: an interview in which Professor John Tribe from the University of Surrey answered questions on trends in tourism (a YouTube clip) was well received (immediately after watching the clip the students asked for more similar videos and said that they found such materials very useful, both, for their language and tourism knowledge), as were an excerpt from a Rick Steves documentary on cultural attractions in Slovenia entitled Ljubljana: Happy Hodgepodge, an episode of the TV series The Office, and the documentary Enron: The Smartest Guys in the Room (2005). Some materials are used for warm-up activities, others as listening comprehension activities (trying to recreate real-life listening situations that involve informal spoken discourse, looking as well as listening, listener expectation, ongoing listener response, speaker attention), and a third category provides an introduction to discussions, new vocabulary, grammar reviews, etc. There are numerous possibilities for incorporating authentic materials into lesson plans. The aim of the selected materials is outlined by the topics and goals of the English courses (three semesters) at the Faculty of Tourism in Brežice. These goals are: asking for information; giving holiday information and business information (from a chart); helping clients make choices; writing a set of instructions; writing and responding to letters of enquiry; writing other types of formal and informal emails; writing CVs and cover letters; taking part in job interviews; writing short texts, invitations and summaries; giving a short presentation; talking and writing about modern day developments and trends in tourism; working with figures; designing a questionnaire and conducting a survey; reporting on the nature and value of tourism in a country; telephone use; taking bookings and filling in booking forms; writing reports; planning package tours and excursions; writing promotional materials and press releases; negotiating; dealing with complaints and compensation claims; giving a guided tour; describing jobs, duties and company and organizational structure; financial trends; talking about share prices, mergers and acquisitions; trade fairs; business abroad, etc. Tourism students are expected to have mastered all these topics by the time they pass the three exams (First Foreign Language 1, 2 and 3). 


\section{Conclusion}

At the Faculty of Tourism of the University of Maribor, experience has shown that developing specific purpose materials and choosing authentic classroom materials is very positive. According to the survey, students' feedback confirms this statement. The students of the Faculty of Tourism actually prefer supplementary authentic materials to coursebooks (coursebooks are still used, but only parts of them) because they find them sufficiently interesting or challenging. Specially designed classroom materials that are put into the Moodle by the teachers also offer opportunities for various activities in lesson planning for teaching, listening, speaking, reading and writing. Another very important aspect of supplementary materials is that they facilitate the teacher's creativity. In a way, a new coursebook for tourism students takes shape in the Moodle during the learning and teaching process. But even if the current materials from the Moodle were in fact published as a coursebook, this up-to-date "coursebook" designed especially for students of the Faculty of Tourism would still need to be supplemented (as are materials in the Moodle) because teaching is a constantly developing process, because new students with different background knowledge enrol in the Faculty of Tourism each year, because the needs of the market and students change, because technology changes, etc. Teaching is an evolving process, which is probably why even the best and the newest coursebooks need to be supplemented with additional materials and eventually again replaced with new coursebooks. Even though the students' answers show that the students feel that coursebooks are not necessary, it is probably easier for the teachers to use coursebooks (especially at the beginning of their teaching careers) and supplement them whenever the need arises.

\section{References}

Balič, Tina (2009). Using Authentic Materials in Teaching English as a Foreign Language. Vienna: DAAM International Publishing.

Chou, Peter Tze-Ming (2010). Advantages and disadvantages of ESL coursebooks. The Internet TESL Journal, Vol. XVI, No. 11, November 2010. (http://iteslj.org/Articles/ChouCourseBooks.html, accessed 15 November 2014)

Corbett, John (2003). An Intercultural Approach to English Language Teaching. London: Cromwell Press Ltd.

Harding, Keith (2007). English for Specific Purposes. Oxford: Oxford University Press.

Hempkin, K. M. \& Majcenovič Kline Barbara (2012). Vocabulary acquisition for future nursing staff: authenticity in the classroom. Scripta Manent (Vol. 7/2). (http://www.sdutsj.edus.si/ScriptaManent/2012_7_2/hempkin_majcenovickline.ht $\mathrm{ml}$. accessed 10 November 2014)

Kachru, B. B. \& C. L. Nelson (2001). World Englishes. A. Burns and C. Coffin, eds. Analysing English in a Global Context. New York: Routledge, 9-25. 
Šabec, Nada \& David Limon (2001). Across Cultures: Slovensko-britansko-ameriško medkulturno sporazumevanje-Slovene-British-American Intercultural Communication. Maribor: Obzorja.

Tomalin, Barry \& Susan Stempleski (1994). Cultural Awareness. Oxford : Oxford University Press.

Ur, Penny (2001). A Course in Language Teaching: Practice and Theory. Cambridge: CUP.

Received December 30, 2014

Accepted for publication February 3, 2015

Author's address:

Fakulteta za turizem Univerze v Mariboru

Cesta prvih borcev 36

8250 Brežice

Slovenija

jasna.potocnik1@um.si (jasnapotocnik@yahoo.com) 